\title{
Design of Robust Current Controller Using GA for Three Level 24-Pulse VSC Based STATCOM
}

\author{
M. Janaki ${ }^{\dagger}$, R. Thirumalaivasan*, and Nagesh Prabhu** \\ ${ }^{\dagger *}$ School of Electrical Eng., VIT University, Vellore, India \\ ** Dept. of Electrical Eng., Canara Engineering College, Mangalore, India
}

\begin{abstract}
A STATic synchronous COMpensator (STATCOM) is a shunt connected voltage source converter (VSC) based FACTS controller using Gate Turn Off (GTO) power semiconductor devices employed for reactive power control. The operation principal is similar to that of a synchronous condenser. A typical application of a STATCOM is voltage regulation at the midpoint of a long transmission line for the enhancement of power transfer capability and/or reactive power control at the load centre. This paper presents the modeling of STATCOM with twenty four pulse three level VSC and Type-1 controller to regulate the reactive current or the bus voltage. The performance is evaluated by transient simulation. It is observed that, the STATCOM shows excellent transient response to step change in the reactive current reference. While the eigenvalue analysis is based on D-Q model, the transient simulation is based on both D-Q and 3 phase models of STATCOM (which considers switching action of VSC).
\end{abstract}

Key Words: FACTS, Genetic Algorithm (GA), Static Synchronous Compensator (STATCOM), Voltage Source Converter (VSC)

\section{INTRODUCTION}

The concept of Flexible AC Transmission System (FACTS) envisages the use of advances in power electronics technology to achieve flexibility in system operation together with fast and reliable control [1]. Fast control over reactive power can allow secure loading of transmission lines closer to their thermal limits, regulate voltage and improve system damping. The availability of high power gate turn off (GTO) thyristors has led to the development of the STATCOM. The STATCOM is a VSC based FACTS device which is used for shunt reactive power compensation. The converter is connected to the system bus through interfacing reactance, which is the leakage reactance of the coupling transformer [2]-[4].

The STATCOM is connected at the mid point of a long transmission line to regulate the voltage and to enhance the power transfer capability. The major advantages of a STATCOM over a Fixed Capacitor-Thyristor Controller Reactor (FC-TCR) type SVC are [3], [4]:

(1) A significant reduction in size can be achieved due to the reduced number of passive elements and their smaller size.

(2) A STATCOM can supply the required reactive current even at low values of bus voltages, while the reactive current capability of a FC-TCR at its limit varies linearly with the voltage.

In this paper a 3-level, 24-pulse voltage source converter

Manuscript received Apr. 29, 2010; revised Mar. 22, 2011

Recommended for publication by Associate Editor Kyo-Beum Lee.

$\dagger$ Corresponding Author: janaki.m@vit.ac.in

Tel: +91-416-220-2360, VIT University

* School of Electrical Eng., VIT University, India

** Dept. of Electrical Engineering College, India
(VSC) is considered for STATCOM configuration with Type-1 controller [5]. The Type-1 controller modulates the magnitude and phase angle of the converter output voltage relative to the supply voltage [1], [2], [6]. The objective of this paper is to present a systematic method for controller parameter optimization based on Genetic Algorithm (GA), while ensuring stability and improvement of the transient response.

This paper is organized as follows: Section II describes the modeling of STATCOM with 3-level 24-pulse VSC. The current controller design is in Section III. The GA based optimization of the controller parameters is described in section IV. Section V gives the conclusion.

\section{Modeling of STATCOM with Three LeVel 24-PULSE VSC}

The schematic of STATCOM is shown in Fig. 1. The STATCOM is connected to the bus (with voltage $V_{s}$ ) through a coupling transformer with resistance and reactance of $R_{S}$ and $X_{S}$, respectively. In the power circuit of the STATCOM, the converter has either a multi-pulse and/or a multilevel configuration. With three-level converter topology the magnitude of the ac output voltage of the converter can be changed by varying the dead angle $\beta$ with fundamental switching frequency [7], [8]. The time period in a cycle during which the converter pole voltage is zero is $\frac{4 \beta}{\omega_{0}}$. The three-level converter topology greatly reduces the harmonic distortion on the ac side [5], [8], [9] and [10]. Here the STATCOM is realized by a combination 24-pulse three level configuration.

A detailed three-phase model of STATCOM is developed by modeling the converter operation by switching functions [5], [10]. 


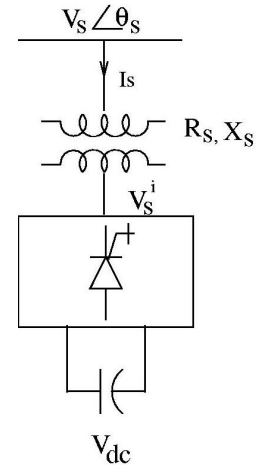

(a) Schematic.

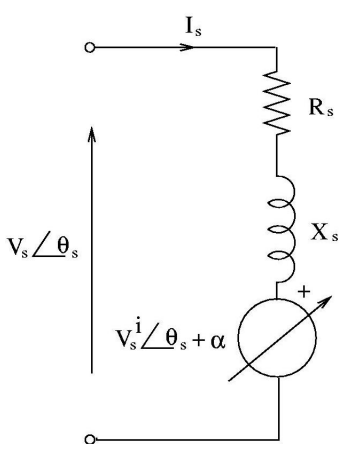

(b) Equivalent Circuit.

Fig. 1. STATCOM shunt FACTS controller.

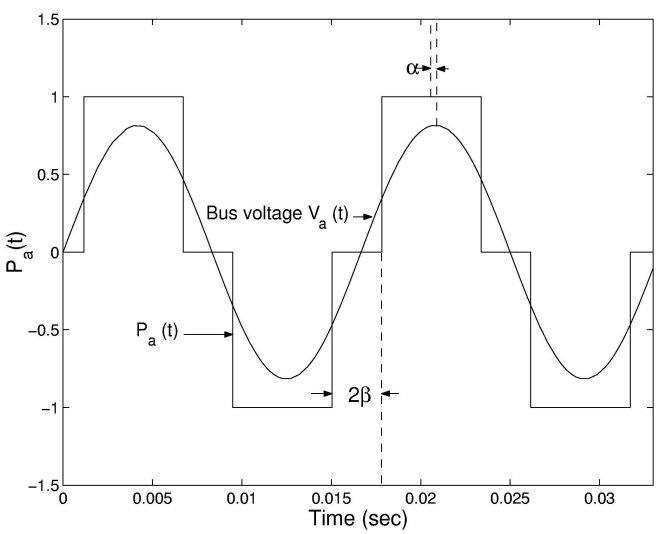

Fig. 2. Switching function for a three level converter.

\section{A. Mathematical Modeling of Three-Level 24-Pulse VSC [8],[10]}

The modeling of three-level VSC is based on switching functions. In three level bridge, the phase potentials can be modulated between three levels instead of two. Each phase can be connected to the positive dc terminal, the midpoint on the dc side or the negative dc terminal.

The switching function $P_{a}(t)$ for phase ' $a$ ' is shown in Fig. 2. The switching functions of phase $b$ and $c$ are similar but phase shifted successively by $120^{\circ}$ in terms of the fundamental frequency.

Assuming that the DC capacitor voltages are:

$$
V_{d c 1}=V_{d c 2}=\frac{V_{d c}}{2}
$$

The converter terminal voltages with respect to the mid point of the dc side ' $N$ ' can be obtained as:

$$
\left[\begin{array}{l}
V_{a N}^{i} \\
V_{b N}^{i} \\
V_{c N}^{i}
\end{array}\right]=\left[\begin{array}{l}
P_{a}(t) \\
P_{b}(t) \\
P_{c}(t)
\end{array}\right] \frac{V_{d c}}{2} .
$$

The converter terminal voltages with respect to the neutral of the transformer can be expressed as:

$$
\left[\begin{array}{l}
V_{a n}^{i} \\
V_{b n}^{i} \\
V_{c n}^{i}
\end{array}\right]=\left[\begin{array}{l}
S_{a}(t) \\
S_{b}(t) \\
S_{c}(t)
\end{array}\right] V_{d c}
$$

where:

$$
S_{a}(t)=\frac{P_{a}(t)}{2}-\left[\frac{P_{a}(t)+P_{b}(t)+P_{c}(t)}{6}\right] .
$$

$S_{a}(t)$ is the switching function for phase ' $a$ ' of a 6-pulse 3level VSC and $V_{d c}$ is the dc side capacitor voltage. Similarly for phase ' $b$ ' $S_{b}(t)$ and for phase ' $c$ ', $S_{c}(t)$ can be derived. The peak value of the fundamental and the harmonics in the phase voltage $V_{a n}^{i}$ are found by applying Fourier analysis on the phase voltage which can be expressed as:

$$
V_{a n}^{i}=\frac{2}{h \pi} V_{d c} \cos (h \beta)
$$

where, $h=1,5,7,11,13$ and $\beta$ is the dead angle (period) during which the converter pole output voltage is zero. We can eliminate the $5^{\text {th }}$ and $7^{\text {th }}$ harmonics by using a twelve-pulse VSC, which combines the output of two six-pulse converters using transformers.

The switching functions for the first twelve-pulse converter are given by:

$$
\begin{aligned}
& S_{1 a}^{12}(t)=S_{1 a}(t)+\frac{1}{\sqrt{3}}\left(S_{1 a}^{1}(t)-S_{1 c}^{1}(t)\right), \\
& S_{1 b}^{12}(t)=S_{1 b}(t)+\frac{1}{\sqrt{3}}\left(S_{1 b}^{1}(t)-S_{1 a}^{1}(t)\right), \\
& S_{1 c}^{12}(t)=S_{1 c}(t)+\frac{1}{\sqrt{3}}\left(S_{1 c}^{1}(t)-S_{1 b}^{1}(t)\right),
\end{aligned}
$$

where:

$$
\begin{aligned}
S_{1 x}^{1}(t) & =S_{1 x}\left[t+\frac{2 \pi}{\omega_{0}} \frac{1}{12}\right] \\
S_{1 x}(t) & =S_{x}\left[t+\frac{\pi}{\omega_{0}} \frac{1}{24}\right], \\
x & =a, b \text { and } c .
\end{aligned}
$$

The switching functions for the second twelve-pulse converter are given by:

$$
\begin{aligned}
& S_{2 a}^{12}(t)=S_{2 a}(t)+\frac{1}{\sqrt{3}}\left(S_{2 a}^{1}(t)-S_{2 c}^{1}(t)\right), \\
& S_{2 b}^{12}(t)=S_{2 b}(t)+\frac{1}{\sqrt{3}}\left(S_{2 b}^{1}(t)-S_{2 a}^{1}(t)\right), \\
& S_{2 c}^{12}(t)=S_{2 c}(t)+\frac{1}{\sqrt{3}}\left(S_{2 c}^{1}(t)-S_{2 b}^{1}(t)\right),
\end{aligned}
$$

where:

$$
\begin{aligned}
S_{2 x}^{1}(t) & =S_{2 x}\left[t+\frac{2 \pi}{\omega_{0}} \frac{1}{12}\right] \\
S_{2 x}(t) & =S_{x}\left[t-\frac{\pi}{\omega_{0}} \frac{1}{24}\right] \\
x & =a, b \text { and } c .
\end{aligned}
$$

The switching functions for a twenty-pulse converter are given by:

$$
\begin{aligned}
S_{a}^{24}(t) & =S_{1 x}^{12}(t)+S_{2 x}^{12}(t), \\
x & =a, b \text { and } c .
\end{aligned}
$$


If the switching functions are approximated by their fundamental components (neglecting harmonics), for a 24-pulse three-level converter, the following is obtained:

$$
V_{a n}^{i}=\frac{8}{\pi} V_{d c} \cos (\beta) \sin \left(\omega_{0} t+\alpha+\theta_{s}\right)
$$

while $V_{b n}^{i}, V_{c n}^{i}$ are phase shifted successively by $120^{\circ}$.

The line current is given by, $i_{a}=\sqrt{\frac{2}{3}} I_{a} \sin \left(\omega_{0} t+\theta_{s}\right)$ while $i_{b}, i_{c}$ are phase shifted successively by $120^{\circ}$.

Neglecting converter losses, the DC capacitor current is given by:

$$
\left[i_{d c}\right]=\left[\begin{array}{lll}
S_{a}^{24}(t) & S_{b}^{24}(t) & S_{c}^{24}(t)
\end{array}\right]\left[\begin{array}{c}
i_{a} \\
i_{b} \\
i_{c}
\end{array}\right] .
$$

A particular harmonics reaches zero, when $2 \beta=\frac{180^{\circ}}{h}$. At $\beta_{\text {optimum }}=3.75^{\circ}$ a three level 24-pulse converter behaves similar to a two level 48 -pulse converter as the $23^{\text {rd }}$ and $25^{\text {th }}$ harmonics are negligibly small.

\section{B. Mathematical Model of STATCOM in D-Q Reference Frame [5], [10]}

When switching functions are approximated by their fundamental frequency components, neglecting harmonics, a STAT$\mathrm{COM}$ can be modeled by transforming the three-phase voltages and currents to D-Q variables using Kron's transformation [11]. The STATCOM can be represented functionally, as shown in Fig. 1.

Magnitude control of the converter output voltage is achieved by modulating the conduction period affected by the dead angle $\beta$ of a converter while the dc voltage is kept constant. The converter output voltage can be represented in the $\mathrm{D}-\mathrm{Q}$ reference frame as:

$$
\begin{aligned}
V_{s}^{i} & =\sqrt{V_{s D}^{i}{ }^{2}+V_{s Q}^{i}{ }^{2}} \\
V_{s D}^{i} & =k_{m} V_{d c} \sin \left(\theta_{s}+\alpha\right) \\
V_{s Q}^{i} & =k_{m} V_{d c} \cos \left(\theta_{s}+\alpha\right) .
\end{aligned}
$$

The following equations in the D-Q variables can be given for describing STATCOM:

$$
\begin{aligned}
\frac{d I_{s D}}{d t}=- & -\frac{R_{S} \omega_{B}}{X_{S}} I_{S D}-\omega_{o} I_{s Q}+\frac{\omega_{B}}{X_{S}}\left[V_{s D}-V_{s D}^{i}\right] \\
\frac{d I_{s Q}}{d t}= & \omega_{o} I_{s D}-\frac{R_{S} \omega_{B}}{X_{s}} I_{S Q}+\frac{\omega_{B}}{X_{s}}\left[V_{s Q}-V_{s Q}^{i}\right] \\
& \frac{d V_{d c}}{d t}=-\frac{\omega_{B}}{b_{c}} I_{d c}-\frac{\omega_{B}}{b_{c} R_{p}} V_{d c}
\end{aligned}
$$

where $I_{d c}=-\left[k_{m} \sin \left(\theta_{s}+\alpha\right) I_{s D}+k_{m} \cos \left(\theta_{s}+\alpha\right) I_{s Q}\right]$.

$I_{s D}$ and $I_{s Q}$ are the D-Q components of the STATCOM current, $\theta_{s}$ is the phase angle of the bus voltage and $\alpha$ is the angle by which the fundamental component of the converter output voltage leads the STATCOM bus voltage $V_{s} . k_{m}$ is the modulation index and for a three-level converter it is a function of the dead angle $\beta$ and is given by $k_{m}=k^{1} \cos \beta$, where $k^{1}=k \rho . k=\frac{4 \sqrt{6}}{\pi}$ for 24-pulse converter. $\rho$ is the transformation ratio of STATCOM interfacing transformer.

In a three level 24-pulse converter, the dc voltage reference may be adjusted by a slow controller to get the optimum harmonic performance at $\beta_{\text {optimum }}=3.75^{\circ}$ in the steady state.

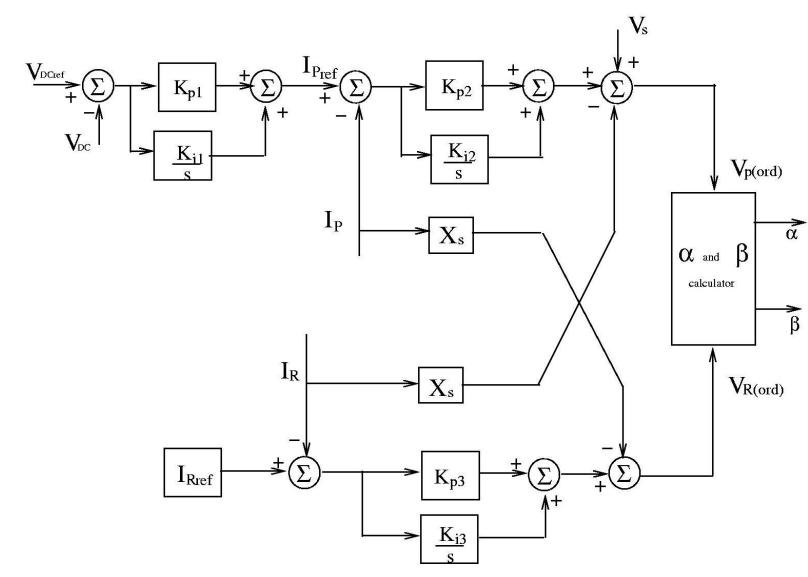

Fig. 3. Type -1 controller for $3-$ level VSC based STATCOM.

\section{STATCOM Current Control (Three-Level VSC)}

The real current drawn by VSC is controlled by the phase angle $\alpha$ and the reactive current by modulating the converter output voltage magnitude as a function of $\beta$. Fig. 3 shows schematic representation of TYPE-1 controller for STATCOM current control. The reactive current reference of the STAT$\mathrm{COM}$ can be kept constant or regulated to maintain the bus voltage magnitude at a specified value.

The real and reactive currents are defined as:

$$
\begin{gathered}
I_{P}=I_{S D} \sin \left(\theta_{s}\right)+I_{s Q} \cos \left(\theta_{s}\right) \\
I_{R}=-I_{S D} \cos \left(\theta_{s}\right)+I_{S Q} \sin \left(\theta_{s}\right) .
\end{gathered}
$$

$\alpha$ and $\beta$ are calculated as:

$$
\begin{gathered}
\alpha=\tan ^{-1}\left[\frac{V_{R(\text { ord })}}{V_{P(\text { ord })}}\right] \\
\beta=\cos ^{-1}\left[\frac{\sqrt{V_{R(\text { ord })}^{2}+V_{P(o r d)}^{2}}}{k^{1} V_{d c}}\right]
\end{gathered}
$$

Values of $I_{P}$ and $I_{R}$ result in positive values when the STATCOM is absorbing real and reactive power.

\section{Current Controller Design}

In this section the design of real and reactive current controller is investigated. To simplify the controller design procedure, the voltage at the STATCOM bus is assumed constant (neglecting the dynamics in the transmission network).

The transient simulation of STATCOM is carried out using both D-Q and 3-phase models in MATLAB-SIMULINK [12]. The step response with 3-phase model of three-level STATCOM with non-optimized controller parameters is shown in Fig. 4.

As can be seen in Fig. 4 the step response of the STATCOM reactive current with non-optimized controller parameters has overshoot during the transition from the capacitive to inductive mode of operation of the STATCOM and it reaches the steady state after 0.04 sec.

Hence, optimizing the controller parameters is required to improve the transient response of the STATCOM. The optimization of the reactive current controller parameters based on GA will be discussed in the following section. 


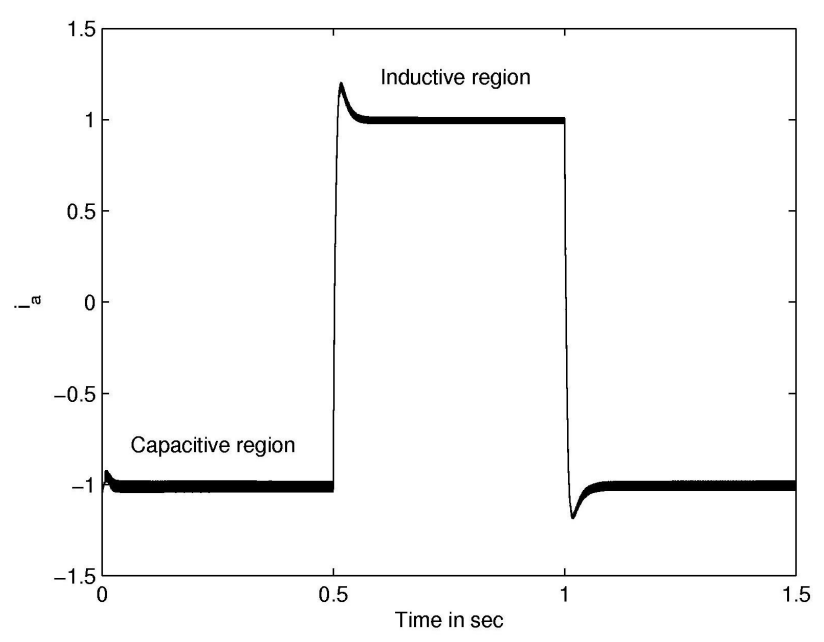

Fig. 4. Step response with $3 \Phi$ model of STATCOM with non-optimaltized controller parameters.

\section{Application of Genetic Algorithm For CONTROLLER PARAMETER OPTIMIZATION}

\section{A. Introduction}

GA has been used for optimizing the parameters of control systems that are complex and difficult to solve with conventional optimization methods [13].

It maintains a set of candidate solutions called population and repeatedly modifies them. Each member of the population is evaluated using a fitness function. The population undergoes reproduction in a number of iterations. One or more parents are chosen stochastically, but strings with higher fitness values have a higher probability of contributing the offspring Genetic operators, such as crossover and mutation are applied to parents to produce offspring. The offspring are inserted into the population and the process is repeated.

Given a random initial population, GA operates in cycles called generations, as follows:

The basic steps involved in GA are:

Step 1: Begin with a randomly generated population of chromosome- encoded "solutions" to a given problem.

Step 2: Calculate the fitness of each chromosome, where the fitness is a measure of how well a member of the population performs at solving the problem.

Step 3: Retain only the fittest members and discard the least fit members.

Step 4: Generate a new population of chromosomes from the remaining members of the old population by applying the operations reproduction, crossover, and mutation.

Step 5: Calculate the fitness of these new members of the population, retain the fittest, discard the least fit, and re-iterate the process.

GA based optimization guarantees system stability under varying operating conditions.

\section{B. Objective Function}

For damping oscillations, a damping factor $\zeta$ of around $10 \%$ to $20 \%$ is considered to be adequate. A damping factor of $10 \%$ would be acceptable to most utilities and can be adopted as the minimum requirement. Further, having the real part of the

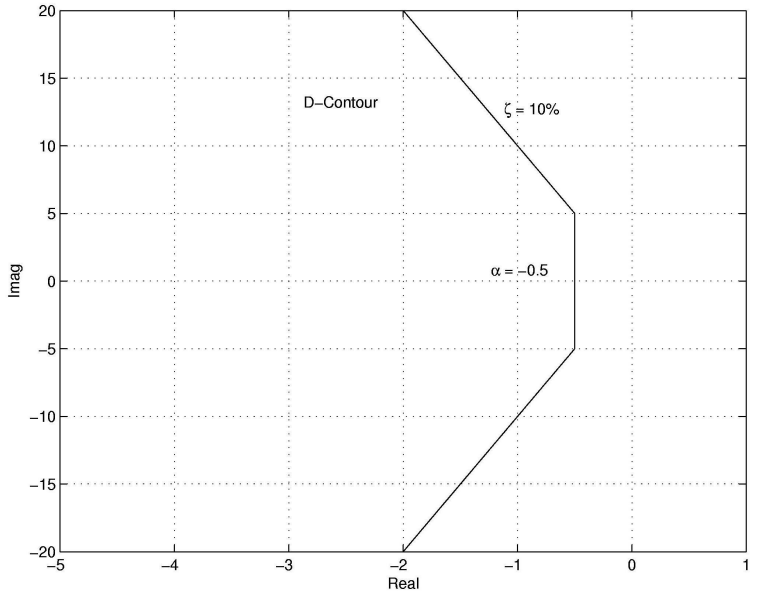

Fig. 5. D-contour with $\alpha=-0.5$ and $\zeta=10 \%$.

eigenvalue restricted to less than a value, say $\alpha$, guarantees a minimum decay rate $\alpha$. The value $\alpha=-0.5$ is to be considered adequate for an acceptable settling time. The closed loop mode location should simultaneously satisfy these two constraints for an acceptable small disturbance response of the controlled system.

If all the closed loop poles are located to the left of the contour shown in Fig. 5, then the constraints on the damping factor and the real part of eigenvalues are satisfied and a well damped small disturbance response is guaranteed. This contour is referred as the D-contour [9], [14].

A system is said to be D-stable if it is stable with respect to this D-contour, i.e. all of its pole lie on the left of this contour. This property is referred to as generalized stability in control literature. This generates a neat specification- the closed loop system should be robustly D-stable, i.e. D-stable for the entire range of operating and system conditions. Hence, a system is said to be 'robust' if, in spite of changes in system and operating conditions, the closed loop poles remain on the left of the D-contour for a specified range of system and operating conditions.

The D-contour in Fig. 5 can be mathematically described as:

$$
f(z)=\operatorname{Re}(z)-\min [-\operatorname{Im}(z), \alpha]=0
$$

where $z \varepsilon C$, is a point on the D-contour and $C$ represents the complex plane.

$J$ is defined as:

$$
J=\max _{i}\left[\operatorname{Re}\left(\lambda_{i}\right)-\min _{i=1,2,3, \ldots, n}\{-\zeta|\operatorname{Im}(z)|, \alpha\}\right]
$$

where $n$ is the number of eigenvalues and $\lambda_{i}$ is the $i^{t h}$ eigen value of the system at an operating point. A negative value of $J$ implies that all the eigenvalues lie on the left of the Dcontour. Similarly some or all eigenvalues will lie on the right of the $\mathrm{D}$ contour if $J$ is positive.

On the basis of these facts, the objective function $E$ is defined as:

$$
\text { Sum Squared Error }(E)=\sum e^{2}
$$

Where $e=i_{\text {Rref }}-i_{R}$

where $i_{R r e f}$ and $i_{R}$ are the reactive current reference input and 
TABLE I

Parameters Used For Optimization with Genetic Algorithm

\begin{tabular}{|l|c|}
\hline \multicolumn{1}{|c|}{ Parameter } & Value / Type \\
\hline Maximum Generations & 20 \\
\hline Population Size & 200 \\
\hline Type of Selection & Normal Geometric [0 0.08] \\
\hline Type of Crossover & Arithmetic [4] \\
\hline Type of mutation & Non uniform [4 20 3] \\
\hline Termination method & Maximum Generation \\
\hline
\end{tabular}

TABLE II

Eigenvalues with Optimal Controller Parameters Based on GA

\begin{tabular}{|c|c|}
\hline $\begin{array}{c}\text { Capacitive Region } \\
i_{R}=-1\end{array}$ & $\begin{array}{c}\text { Inductive Region } \\
i_{R}=1\end{array}$ \\
\hline$-733.87 \pm \mathrm{j} 1297.9$ & $-733.37 \pm \mathrm{j} 1570.6$ \\
\hline-649.88 & -649.88 \\
\hline-25.134 & -25.134 \\
\hline-1.4425 & -1.4442 \\
\hline-11.137 & -11.137 \\
\hline
\end{tabular}

reactive current output of the STATCOM, respectively.

Hence, the optimization problem can be stated as:

\section{Minimize E}

Subjected to $J \leq 0$

In addition to this, the boundaries of the optimal parameters are:

$$
\begin{array}{ll}
k_{p 1_{\text {min }}} \leq k_{p 1} \leq k_{p 1_{\text {max }}} & k_{i 1_{\text {min }}} \leq k_{i 1} \leq k_{i 1_{\text {max }}} \\
k_{p 2_{\text {min }}} \leq k_{p 2} \leq k_{p 2_{\text {max }}} & k_{i 2_{\text {min }}} \leq k_{i 2} \leq k_{i 2_{\text {max }}} \\
k_{p 3_{\text {min }}} \leq k_{p 3} \leq k_{p 3_{\text {max }}} & k_{i 3_{\text {min }}} \leq k_{i 3} \leq k_{i 3_{\text {max }}}
\end{array}
$$

Genetic Algorithm is adopted to obtain the optimal parameters of TYPE-1 controller [14], [15]. The parameters used with GA are given in Table I.

The Eigenvalues of the system with TYPE- 1 controller and the optimized controller parameters are shown in Table II. Fig. 6 shows location of eigenvalues of the STATCOM in the complex plane for the entire inductive and capacitive range of operation. The eigenvalues are lying on left half of the Dcontour with the optimal controller parameters. Thus the GA based optimization ensures that the system is robustly D-stable for the various operating points under consideration.

The transient simulation of STATCOM is carried out using both the D-Q and 3-phase models in MATLAB-SIMULINK [12].

The step response with the 3-phase model of three-level STATCOM with the optimal controller parameters is shown in Fig. 7.

It can be seen in Fig. $7 \& 8$ that the transition from capacitive to inductive mode of operation of the STATCOM is very fast and it takes less than $0.005 \mathrm{sec}$ to reach the steady state. It is to be noted that the transient response of the STATCOM is significantly improved. The steady state oscillations in the reactive current of Fig. 7 are due to the harmonics in the converter output voltage. Thus with the optimal controller parameters the speed of the response of the STATCOM is increased and hence the transient response is improved.

\section{CONCLUSIONS}

In this paper a systematic method for controller parameter optimization based on Genetic Algorithm (GA) for the design

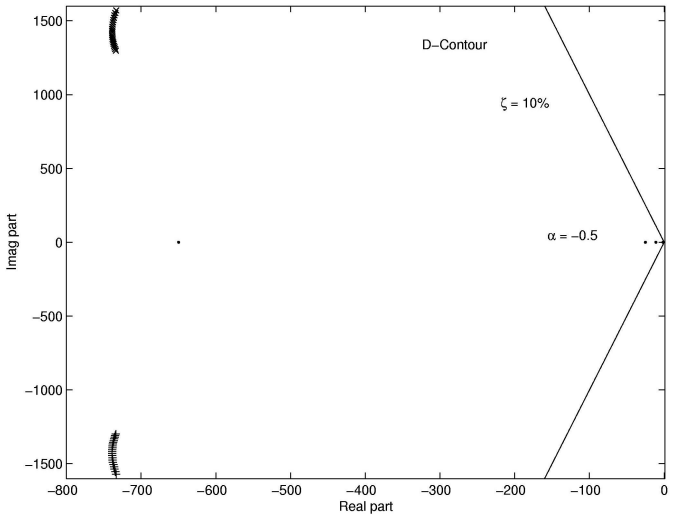

Fig. 6. Location of eigenvalues of STATCOM with optimal controller parameters.

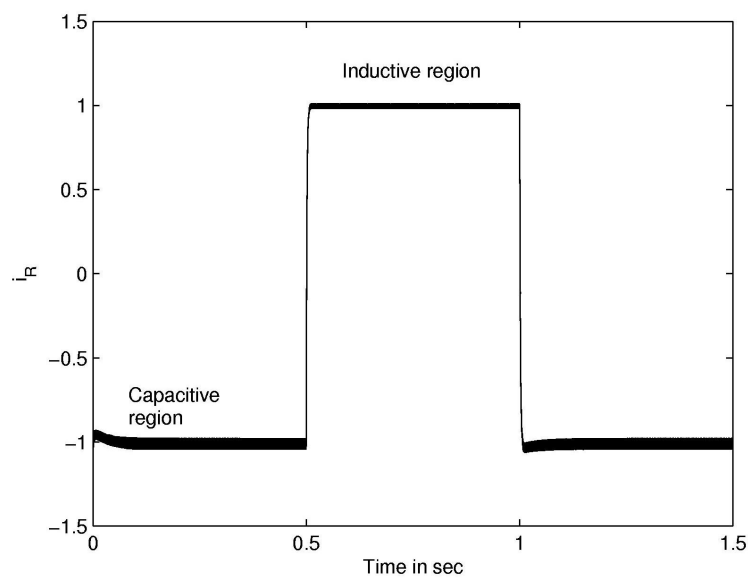

Fig. 7. Step response with $3 \Phi$ model of STATCOM with optimal controller parameters.

of STATCOM real and reactive current controller was presented. The GA based optimization ensures that the system is robustly D-stable in the entire range of operation and system conditions. The performance of the designed controller is evaluated and it is observed that the STATCOM with the optimized controller parameters provides an excellent transient response.

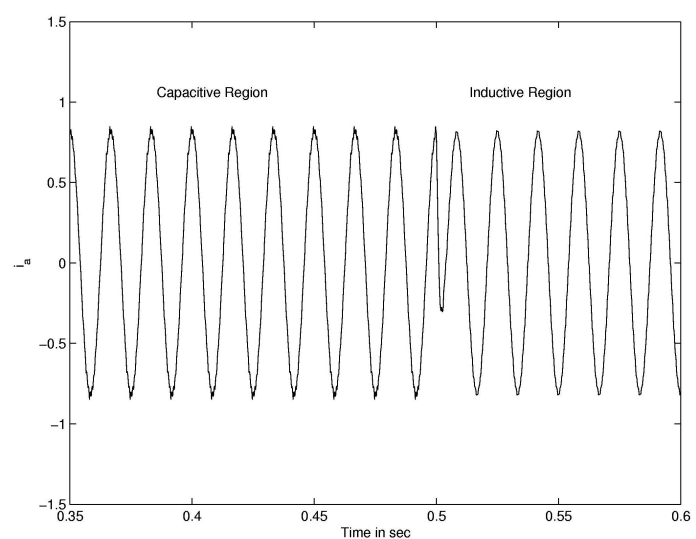

Fig. 8. Phase 'a' current of STATCOM with optimal controller parameters. 


\section{REFERENCES}

[1] N. G. Hingorani, "Flexible AC transmission system," IEEE spectrum, pp.40-45, Apr. 1993.

[2] C. Schauder and H. Mehta, "Vector analysis and control of advanced static var compensators," IEE Proceedings, Part C, Vol. 140, No. 4, 299-306, 1993.

[3] Y. Sumi, Y. Haramuto, T. Hasegawa, M. Yano, K. Ikeda, and T. Matsuura, "New static VAR control using force commutated inverters," IEEE Trans. Power App. Syst.*, Vo. PAS-100, No. 9, pp. 4216-4224, Sep. 1981.

[4] L. Gyugyi, "Reactive power generation and control by thyristor circuits," IEEE Trans. Ind. Appl., Vol. IA-15, No. 5, 531-532, Sep. 1979.

[5] K. R. Padiyar and N. Prabhu, "Design and performance evaluation of subsynchronous damping controller with STATCOM," IEEE Trans. Power Del., Vol. 21, No. 3, pp. 1398-1405, Jul. 2006.

[6] K. R. Padiyar and A. M. Kulkarni, "Design of reactive current and voltage controller of static condenser," Int. J. Electr. Power Energy Syst., Vol. 19, No. 6, pp. 397-410, Aug. 1997.

[7] K. R. Padiyar and V. S. Prakash, "Tuning and performance evaluation of damping controller for a STATCOM," Int. J. Electr. Power and Energy Syst., Vol. 25, No. 2, pp. 155-166, Feb. 2003.

[8] K. R. Padiyar and N. Prabhu, "Analysis of sub synchronous resonance with three level twelve-pulse VSC based SSSC," in Proc. IEEE TENCON-2003, Vol. 1, pp. 76-80, 2003.

[9] K. R. Padiyar, FACTS Controllers in Power Transmission and Distribution, New age International (P) Ltd, 2007.

[10] N. Prabhu, "Analysis of SubSynchronous Resonance with Voltage Source Converter based FACTS and HVDC Controllers," Ph.D. dissertation, IISc Bangalore, 2004.

[11] K. R. Padiyar, Power System Dynamics - Stability and Control, Second Edition, Hyderabad, B.S. Publications, 2000.

[12] Using MATLAB-SIMULINK, The MathWorks, Inc., Natick, MA, 1999.

[13] Goldberg, Genetic Algorithm in search, Optimization and Machine Learning, Addison Wesley Reading, 1989.

[14] R. Singh, "A Novel Approach for Tuning of Power System Stabilizer Using Genetic Algorithm," M.Sc. dissertation, Indian Inst. of Sci., Bangalore, India, Jul. 2004

[15] A. L. B. Do Bomfim, G. N. Taranto, and D. M. Falcao, "Simultaneous tuning of power system damping controllers using genetic algorithms," IEEE Transactions on Power Syst., Vol. 15, No. 1, pp. 163-169, Feb. 2000.

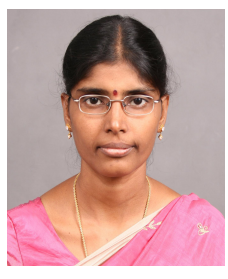

M. Janaki received her B.E. from Madras University, Chennai, India, in 1996 and her M.E. from the College of Engineering, Anna University, Guindy, Chennai, India, in 2002. She is an Assistant Professor (Senior) in the School of Electrical Engineering at VIT University, Vellore, India. She is currently pursuing her Ph.D. in the Department of Electrical Engineering, JNTU Hyderabad, India. Her research interests include FACTS, HVDC and power systems.

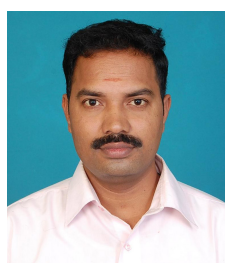

R. Thirumalaivasan received his B.E. from Madras University, Chennai, India, in 1999 and his M.Tech degree from the College of Engineering, Anna University, Guindy, Chennai, India, in 2002. He is an Assistant Professor (Senior) in the School of Electrical Engineering at VIT University, Vellore, India. He is currently pursuing his Ph.D. in the Department of Electrical Engineering, JNTU Hyderabad, India. His research interests include FACTS, HVDC, the real-time digital simulation of power electronics and power systems.

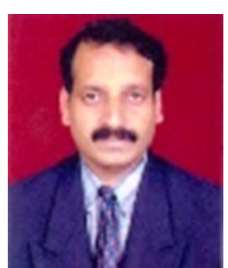

Nagesh Prabhu received his diploma in Electrical Engineering from Karnataka Polytechnic, Mangalore, India, in 1986 and he graduated with a degree in Electrical Engineering from the Institution of Engineers, India, in 1991. He received his M.Tech. in Power and Energy Systems from N.I.T. Karnataka, India, (formerly Karnataka Regional Engineering College) in 1995, and his Ph.D. from the Indian Institute of Science, Bangalore, India, in 2005. He is presently the Principal of Canara Engineering College Mangalore, India. He was with the N.M.A.M. Institute of Technology, Nitte, India, from 1986 to 1998, the J.N.N. College of Engineering Shimoga, India, from 1998 to 2006 and the Vel Multi Tech Sri

Rangarajan Sakunthala Engineering College from 2006 to 2008. His research interests include power system dynamics and control, HVDC, FACTS and custom power controllers. Dr. Prabhu is a Life Member of the Indian Society for Technical Education, a Member of IEEE and a Fellow of ISLE, India. 